\title{
Cyclic AMP Induces Changes in Distribution and Transport of Organelles Within Growth Cones of Aplysia Bag Cell Neurons
}

\author{
Paul Forscher, Leonard K. Kaczmarek,' JoAnn Buchanan, and Stephen J Smith \\ The Howard Hughes Medical Institute Section of Molecular Neurobiology, and 'Department of Pharmacology, Yale School \\ of Medicine, New Haven, Connecticut 06510
}

This report examines CAMP-induced regulation of directed organelle transport in bag cell neuron growth cones using video-enhanced differential interference contrast (DIC) microscopy (Allen et al., 1981; Inoue, 1981) and digital image analysis techniques. Under control conditions, organelle transport is evident in the central cytoplasmic regions of bag cell neuron growth cones, but not in lamellae. Motility of lamellae takes the form of slow $(<0.01 \mu \mathrm{m} / \mathrm{sec})$ extension of margins and ruffling motions that propagate as waves (velocity, $\sim 0.07 \mu \mathrm{m} / \mathrm{sec}$ ) in a retrograde direction. Application of forskolin and a phosphodiesterase (PDE) inhibitor at concentrations known to induce changes in bag cell protein phosphorylation resulted in (1) rapid extension of directed organelle transport into lamellae, and (2) inhibition of the retrograde ruffling waves. These changes effected transformation of lamellae into neurite endings packed with microtubules and organelles, a large proportion of which appeared to be neurosecretory granules. The effects were reversible, dose-dependent, potentiated by a variety of PDE

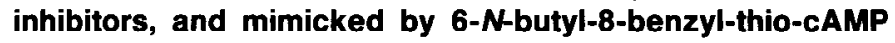
(BT-CAMP). Though forskolin may normally promote depolarization and $\mathrm{Ca}$ entry, these changes in growth cone structure are not secondary to influx of external $\mathrm{Ca}$, as they persist in Ca-free/EGTA solutions; furthermore, they do not resemble the effects of depolarization induced by perfusion with elevated $\mathrm{K}$ solutions. The CAMP-induced changes in growth cone morphology that we report here suggest a possible role for protein phosphorylation in promoting growth cone differentiation and structural changes accompanying secretion.

Little is known about the dynamic control of neuronal organelle traffic. How do neurons tailor transport and packaging of secretory and constitutive materials to the needs of remote nerve terminals during periods of growth and development or secretory activity? What are the signal transduction mechanisms responsible for triggering changes in organelle transport? How generally applicable are recent findings that neurotransmitters, intracellular $\mathrm{Ca}$, and electrical activity can control neurite growth

\footnotetext{
Received Dec. 17, 1986; revised Apr. 7, 1987; accepted Apr. 23, 1987.

This work was supported by the Howard Hughes Medical Institute, NIH Grant NS16671, and a Whitaker Foundation Grant to S.JS., NIH Grant NS07914 to P.F., and NIH Grant NS18492 to L.K.K. We wish to thank Tom Capo and the Howard Hughes Medical Institute Marine Mariculture Facility at Woods Hole, MA, for the supply of laboratory-reared Aplysia californica and for helpful suggestions.

Correspondence should be addressed to Dr. Paul Forscher, Section of Molecular Neurobiology, Yale School of Medicine, 333 Cedar Street, New Haven, CT 06510. Copyright (C) 1987 Society for Neuroscience $0270-6474 / 87 / 113600-12 \$ 02.00 / 0$
}

and structure (Haydon et al., 1984; Cohan and Kater, 1986; Jones et al., 1986)? We have examined the actions of cAMP and $\mathrm{Ca}$ on organelle transport and distribution in isolated bag cell neuron growth cones from Aplysia californica in an effort to address some of these questions.

The bag cell neurons provide several advantages for the study of second messenger-induced modification of neuronal properties. Although the neurons normally display no spontaneous electrical activity, they can be stimulated to generate a longlasting afterdischarge during which they release several neuroactive peptides (Kupferman and Kandel, 1970; Kaczmarek et al., 1978; Stuart et al., 1980). In vivo, this discharge triggers the onset of a sequence of reproductive behaviors. An increase in intracellular cAMP levels occurs in the bag cell neurons at the beginning of the discharge and may initiate several events that support prolonged secretion. Elevations of cAMP in the bag cell neurons have been shown to alter the amplitude and kinetics of several potassium conductances, enhance action potentials, and promote repetitive discharge (Kaczmarek et al., 1980; Kaczmarek and Strumwasser, 1981, 1984; Strong, 1984; Strong and Kaczmarek, 1986). In addition, elevation of cAMP increases the synthesis of the precursor to the secreted peptides (Bruehl and Berry, 1985) and accelerates the processing of this prohormone (E. Azhderian and L. K. Kaczmarek, personal communication).

When bag cell neurons are placed in primary culture, they exhibit many of the properties of cells in situ (Kaczmarek et al., 1979); in addition, sprouting and profuse neurite outgrowth occur during the first $48-72 \mathrm{hr}$ after plating. During this phase of rapid neurite growth in vitro, neurite tips have growth cones with large fanlike lamellae. This simple system may provide an opportunity to investigate regulation of neuronal differentiation, specifically, the structural and biochemical changes involved in converting growth cones into neurosecretory terminals.

We have found that treatments known to elevate intracellular cAMP in bag cell neurons dramatically and rapidly alter the pattern of organelle transport and distribution in growth cones. Cyclic AMP elevation induces extension of directed organelle transport into typically organelle-free lamellipodial domains, resulting in the reversible transformation of lamellae into bulbous endings packed with neurosecretory granules. Perhaps the same signal that is used to coordinate neurosecretion in mature bag cells is used during development in target recognition and participates in the transformation of growth cones into mature neurosecretory terminals.

\section{Materials and Methods}

Cell culture. Laboratory-reared Aplysia californica were provided by the Howard Hughes Medical Institute Marine Mariculture Facility at Woods 
Hole, MA. Dissociated bag cell neurons were produced by a procedure adopted from Kaczmarek et al. (1979). Abdominal ganglia were incubated at $22^{\circ} \mathrm{C}$ for $18 \mathrm{hr}$ in L-15 medium supplemented with seawater salts and $50 \mu \mathrm{g} / \mathrm{ml}$ gentamycin sulfate (L-15 ASW), plus $1.25 \%$ dispase (Boehringer Mannheim). After removal of connective tissue capsules, bag cell clusters were gently triturated, using a plastic micropipette tip, and seeded onto $22 \times 22 \mathrm{~mm}$ acid-cleaned no. 1 glass coverslips previously coated with high-molecular-weight $(>300,000)$ poly-D-lysine (Sigma). Cells were maintained at $15^{\circ} \mathrm{C}$ in $35 \mathrm{~mm}$ plastic petri dishes containing $3 \mathrm{ml} \mathrm{L}-15$ ASW until use.

Video-enhanced light microscopy. Bag cell neurons in vitro do not survive passage through an air-fluid interface; therefore a method of mounting cells directly in a covered chamber prior to removal from a $35 \mathrm{~mm}$ tissue culture dish was devised. Simple double-coverslip chambers were made by attaching thin $(150-300 \mu \mathrm{m})$ glass or plastic shims along 2 parallel edges of a coverslip to act as spacers; this assembly was then attached to the coverslip bearing the cells, creating a hollow chamber with 2 open ends suitable for perfusion. Dow-Corning high-vacuum silicone grease was used to adhere components. Chambers with this construction retain medium over the captured cells by capillary action, facilitating coverslip cleaning and mounting on the microscope stage without cell damage caused by dehydration.

Light microscopy was performed using either a Zeiss IM-35 or an optical bench inverted microscope, both equipped with DIC optics. Zeiss objectives (63/1.4 planapo and 63/1.25 neofluar) and an oil-immersion condenser (NA 1.4) were used. Video images were obtained using newvicon tube type cameras. Images were recorded on video tape or digitized directly from the camera output. Digital image processing was performed using an Imaging Technology PCVISION frame grabber in an IBM-AT host computer. Video images were photographed directly from the video monitor with a $35 \mathrm{~mm}$ camera.

Solutions. Artifical seawater (Na-ASW) contained (in mM) $400 \mathrm{NaCl}$, $10 \mathrm{KCl}, 15$ IIEPES, $10 \mathrm{CaCl}_{2}$, and $55 \mathrm{MgCl}_{2}$. Ca-free ASW was made by equimolar substitution of $\mathrm{MgCl}_{2}$ for $\mathrm{CaCl}_{2}$. High-K-ASW solutions were made by equimolar substitution of $\mathrm{KCl}$ for $\mathrm{NaCl}$. Solutions were passed through a $0.45 \mu \mathrm{m}$ membrane filter and adjusted to $\mathrm{pH} 7.6$ prior to use.

Forskolin (Calbiochem) and RO-20-1724 were dissolved in dimethyl sulfoxide (DMSO) to make $100 \mathrm{~mm}$ stock solutions, yielding maximal final DMSO concentrations of $0.1 \%$ in test solutions. In control experiments, $0.1 \%$ DMSO had no apparent effects on organelle distribution or transport. In other experiments, the presence of $0.1 \%$ DMSO vehicle in both control and test solutions also did not affect our results. Theophylline (Sigma) and 6- $\mathrm{N}$-butyl-8-benzylthio-cAMP (a gift of Dr. J. Miller of Stanford Research Institute) were added directly to test solutions.

Cells werc perfused with Na-ASW for at lcast $30 \mathrm{~min}$ beforc cxposurc to test solutions; continuous perfusion was maintained at all times. Experiments were performed at room temperature.

Electron microscopy. For electron microscopy, cells were fixed in $2.9 \%$ glutaraldehyde (EMS, Ft. Washington, PA) in ASW containing $1 \mathrm{~mm}$ GTP (Sigma) at 1200 mosmol. A pH of 6.9 was used to stabilize microtubules (Luftig et al., 1977). Cells were further processed according to the method of McDonald (1984) to maximize microfilament preservation. Following dehydration, the cultures were embedded in Embed 812 (EMS, Ft. Washington, PA). After polymerization, glass coverslips were removed by treatment with hydrofluoric acid (Moore, 1975). The plastic wafer was surveyed by light microscopy, and appropriate cells were cut out and attached to a blank stub with cyanoacrylate cement. The first $1 \mu \mathrm{m}$ of the surface was cut, and thin sections were collected onto Formvar-coated slot grids. Following staining with uranyl acetatc and lead citrate, the grids were viewed in a Jeol 100CXII electron microscope at $80 \mathrm{kV}$ accelerating voltage.

\section{Results}

Central and peripheral domains in growth cones

Isolated bag cell neurons plated on glass or glass coated with poly-D-lysine sprout and regenerate neurites with large (10-50$\mu \mathrm{m}$-wide) growth cones within $24 \mathrm{hr}$ after plating. Fast organelle transport is readily observable in real time video-enhanced DIC recordings. At $22-25^{\circ} \mathrm{C}$, organelle transport rates range from 0.5 to $3 \mu \mathrm{m} / \mathrm{sec}$.

The transport activity we report here consists mainly of the translocation of spherical $160-200 \mathrm{~nm}$ peptidergic dense core secretory granules. These granules constitute the major proportion of organelles in distal neuritic regions and are large enough to be readily detected by our optical system. We also observe transport of elongated organelles that are probably mitochondria. The electron micrograph of Figure 1 illustrates typical organelle distribution in a growth cone fixed under control conditions. Large, electron-dense secretory granules (Frazier et al., 1967; Kreiner et al., 1986) are present in the neurite shaft and extend into the proximal region of the growth cone. The density of organelles, including that of peptide granules, decreases in the peripheral lamellipodial region of the growth cone, as has been observed in other cell types (Yamada et al., 1971; Letourneau, 1983; Tosney and Wessells, 1983). Microtubules roughly colocalize with the large, dense core granules, extending in linear arrays from the neurite shaft into the proximal growth cone area. Microtubule density is low in lamellae, and microtubules observed in this region do not appear to be organized in linear grouped arrays, as are observed in axons. Mitochondria and a small population of clear vesicles are also sometimes present in lamellae.

A microfilament network forms the core of filopodia. These filaments project proximally in bundles that appear to interact with distal microtubule ends, as observed by others (Letourneau, 1983, 1985; and Fig. 1C).

To distinguish between the different forms of motility we observe in growth cone cores and lamellae, we will adopt the central $(\mathrm{C})$ versus peripheral $(\mathrm{P})$ cytoplasmic domain convention proposed by Bridgman et al. (1986). Aplysia neuron growth cone cores have $\mathrm{C}$ domain characteristics-high organelle and microtubule density - and exhibit continuous, directed organelle movements. In contrast, lamellae have $\mathbf{P}$ domain characteristics-intermittent organelle movements, relatively low organclle density, and high f-actin content. (Studics using cytochalasin-b or rhodamine-conjugated phalloidin to disrupt or label actin indicate a high relative actin content in lamellae; data not shown.)

When observed in video-enhanced DIC microscopy, organelle movement along bag cell neurites or axons has an organized, linear character, probably as a result of translocation along microtubules (Allen et al., 1985; Koonce and Schliwa, 1985; Bridgman et al., 1986; see Schnapp and Reese, 1986, for a review). Organelles move into and out of growth cones under control conditions; however, transport is restricted mostly to the growth cone core, which represents the most distal extension of the $\mathrm{C}$ domain. Individual organelles or groups of several organelles linked together sometimes ventured into the $\mathbf{P}$ domain along linear trajectories; however, such events were infrequent, isolated, and transient. Many organelles appeared to reverse their direction of transport in the transition zone between the $\mathrm{C}$ and $\mathrm{P}$ domains, as if a physical barrier to transport existed at the C-P domain interface (see Vale et al., 1985c; Bridgman et al., 1986). Organelles sometimes moved several microns into the $P$ domain and then reversed direction, returning to the $\mathrm{C}$ domain. Despite these occasional organelle sorties into the $\mathrm{P}$ domain, there was always a clear delineation between the microtubule and organelle-rich growth cone core and the lamellipodium. Figure $2 A$ is a video-enhanced DIC image of a growth cone, illustrating the static features of the delineation between $\mathrm{C}$ - and P-type cytoplasmic domains that are typically observed under control conditions.

Multiple images were acquired at timed intervals, followed 

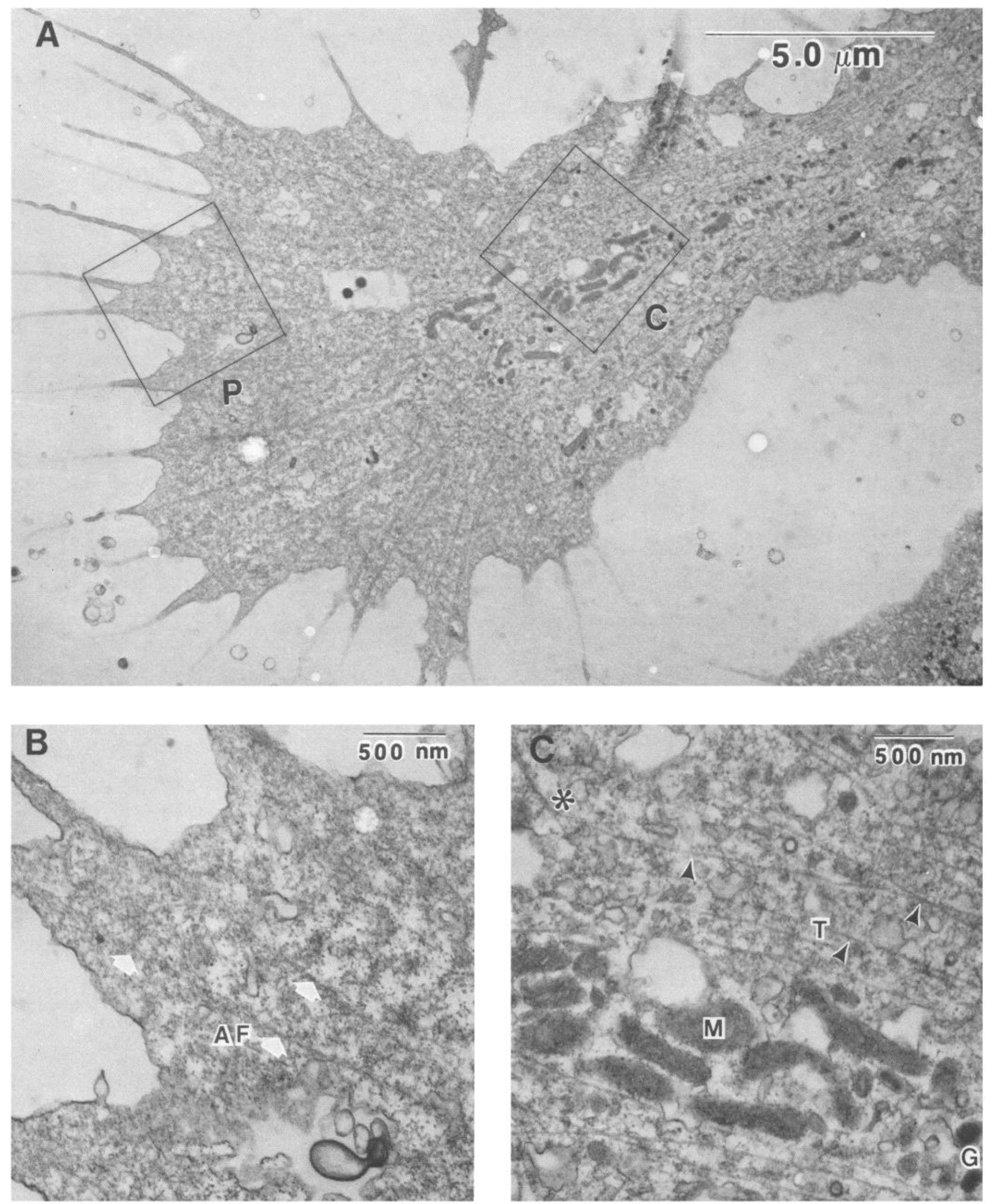

Figure 1. Electron micrographs of a bag cell neuron growth cone showing ultrastructure and cytoplasmic domains. $A$, Growth cone sectioned close to the coverslip-cell interface illustrating peripheral $(P)$ and central $(C)$ cytoplasmic domains. Boxed areas are shown at higher magnification in $B$ and $C$. $B$, Peripheral domain with actin filament bundles indicated $(A F$, arrows). $C$, Central domain containing mitochondria $(M)$, microtubules ( $T$, arrowheads) and dense core secretory granules $(G)$. Note association between microtubule and actin filament bundle (asterisk). 

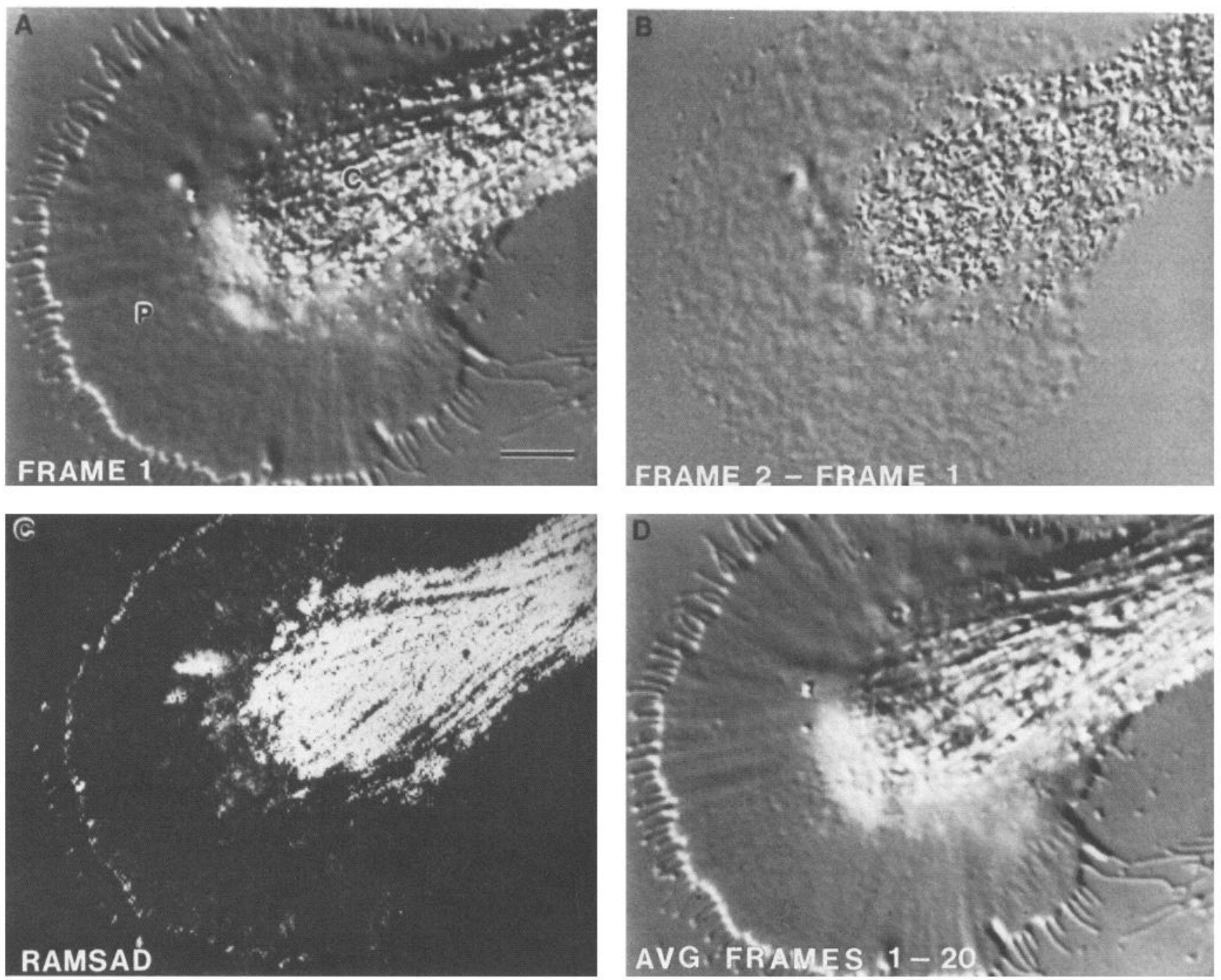

Figure 2. Organelle motility and growth cone morphology. Twenty video frames were digitized at 3.5 sec interframe intervals and used for this analysis. $A$, A single digitized frame of a growth cone under control conditions (Na-ASW; video-enhanced DIC image). Central $(C)$ and peripheral $(P)$ cytoplasmic domains are indicated. $B$, Difference between 2 video frames sampled 3.5 sec apart. Zero difference is represented by midscale gray brightness (background). $C$, Root-mean-square average of differences (RMSAD) over a 20 -frame series representing average movement during the $66.5 \mathrm{sec}$ sampling period. Areas of greater movement are coded by lighter shades of gray. As RMS values are already positive, zero is represented by black level here. $D$, Sum of all 20 frames highlights nonmoving regions of the growth cone. Scale bar, $5 \mu \mathrm{m}$.

by digital image analysis to characterize the dynamic properties of growth cone motility and the movement of organelles within growth cones. Figure $2 B$ represents the arithmetic difference between 2 frames obtained $3.5 \mathrm{sec}$ apart. Motion during the interframe interval causes pixel values in the difference image to deviate from zero, represented here as a midscale gray brightness. In this 2-frame difference image, organelle transport caused pixel differences in the central domain. Pixel differences from midscale gray (background gray level) can also be observed in the lamella. These differences are caused by slow, wavelike undulations of the veil, which propagate in a retrograde direction. Retrograde waves are discussed further below (Fig. 4).

A larger sample of motion information can be summarized by averaging a succession of difference images. For this purpose, it is most informative to use a root-mean-square (RMS) type of average. We call this averaging process RMSAD (root-meansquare average of differences). RMSAD images provide dynamic information in a still-frame image and thus provide a useful technique for comparing and contrasting motility phenomena under differing conditions. The RMSAD image of Figure $2 C$ was calculated using a sequence of 20 images sampled at 3.5 sec intervals. Movement due to organelle transport in the central domain is clearly evident from the relative brightness of this region. There is also evidence of movement in filopodia and near the C-P domain transition zone in this growth cone. The alternation of light and dark longitudinal bands in the $\mathrm{C}$ domain results from the predominance of organelle transport along the ridges that are evident in Figure 2, $A$ and $D$. These ridges probably correspond to microtubule bundles that serve as the major organelle transport routes. To examine the spatial distribution of motility patterns, it is often useful to portray both static and dynamic aspects of the cell in one image. Cellular landmarks that do not move during the sampling period are lost in the RMSAD image; however, by digitally superimposing RMSAD and DIC images, one image can be obtained that contains both static and dynamic information. In Figure 2, $A$ and $C$ have been 
Figure 3. Digital superimposition of RMSAD and DIC images illustrates both dynamic and structural features of growth cones. RMSAD image gray scales were transposed into a pseudocolor spectrum and then overlaid on a high-pass-filtered DIC image of the same field. Warmer hues correspond to regions of greater movement. Growth cone as in Figure $2 C$, control Na-ASW.

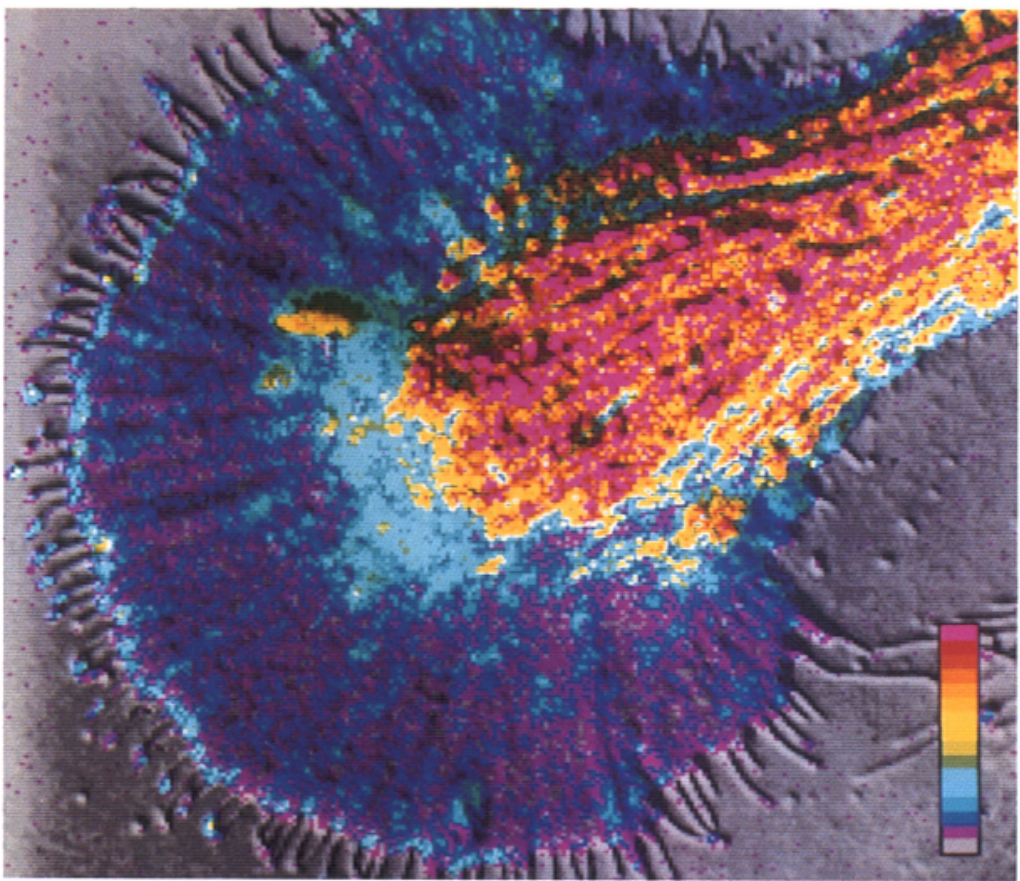

Figure $2 D$ shows the mean of the same 20 frames used in calculating the RMSAD in Figure $2 C$. Features of the cell that do not move are emphasized in the mean image, whereas features in rapid motion are lost in this averaging process. Note
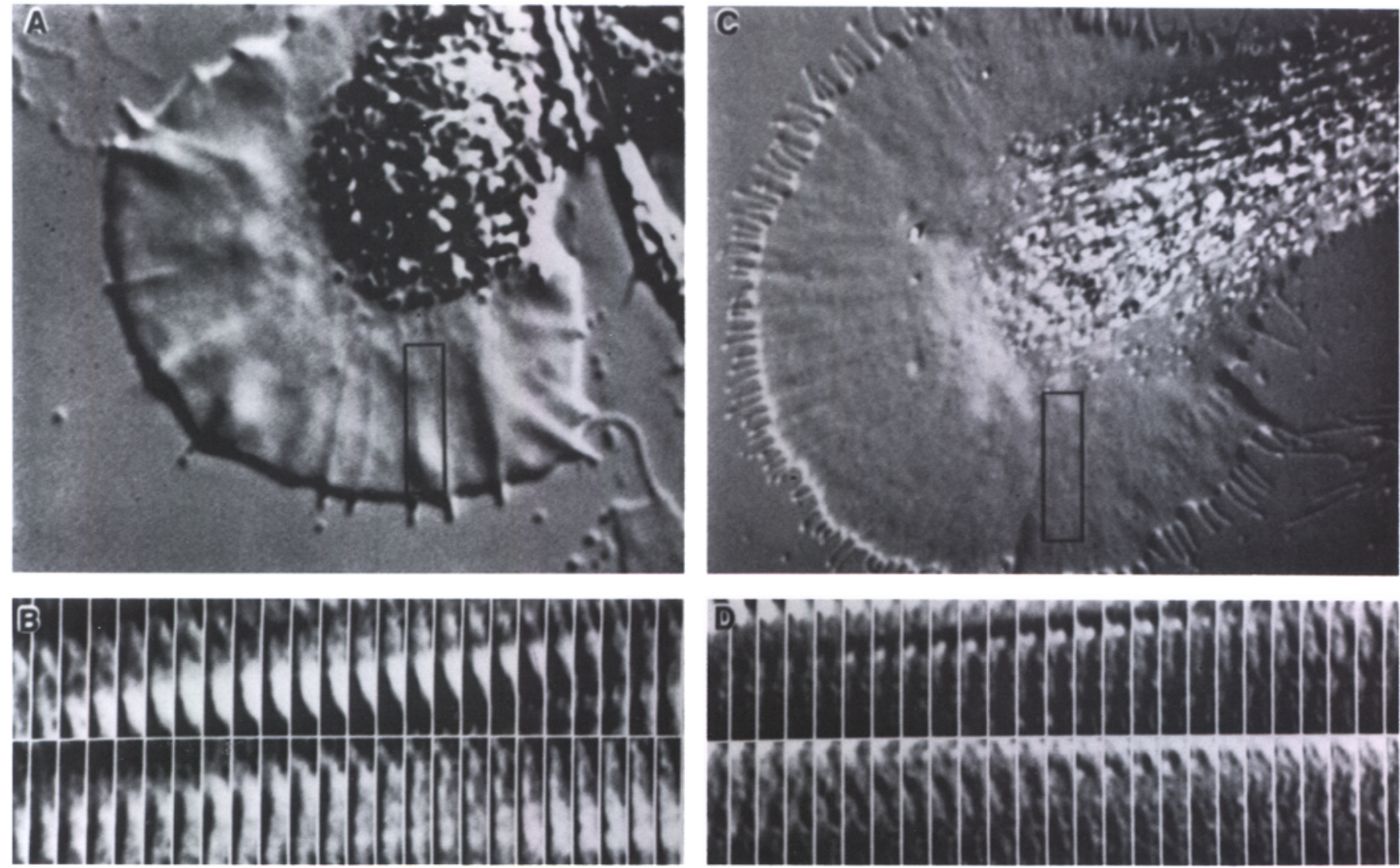

Figure 4. Retrograde waves propagate through lamellae. A, Video-enhanced DIC image indicating the AOI $($ rectangle; $1.1 \times 5.8 \mu \mathrm{m})$ analyzed for retrograde wave activity. $B$, Video sequence of large waves captured at $2 \mathrm{sec}$ intervals from the AOI in $A$. Note that diagonal slope of the wave front is proportional to wave velocity $(0.076 \mu \mathrm{m} / \mathrm{sec})$. C, Wave analysis on the same growth cone as in Figure 2 . AOI marked as in $A(1.6 \times 8.1$ $\mu \mathrm{m}) . D$, Video sequence of smaller waves captured with $2 \mathrm{sec}$ frame intervals. Wave velocity, $0.072 \mu \mathrm{m} / \mathrm{sec}$. 
$\mathrm{Na}-\mathrm{ASW}$ Control

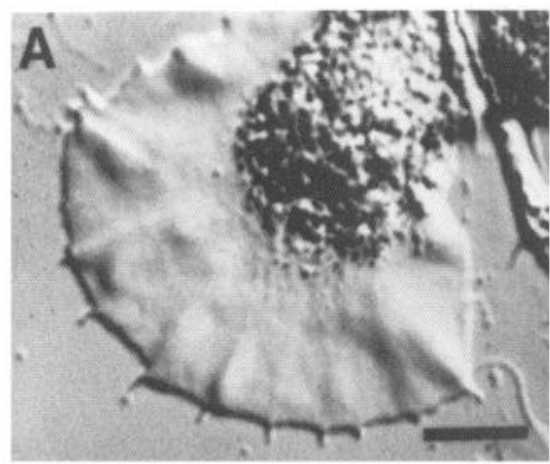

FSK / TH

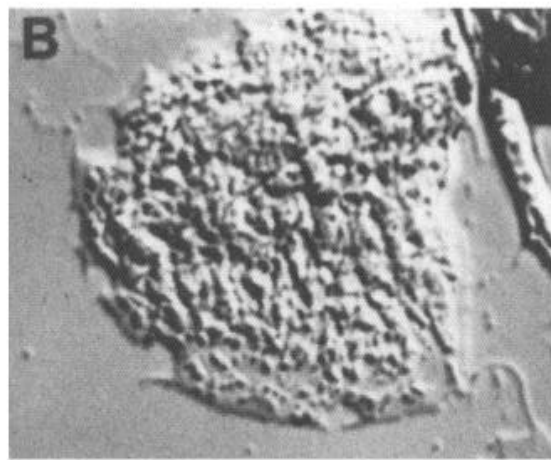

Recovery

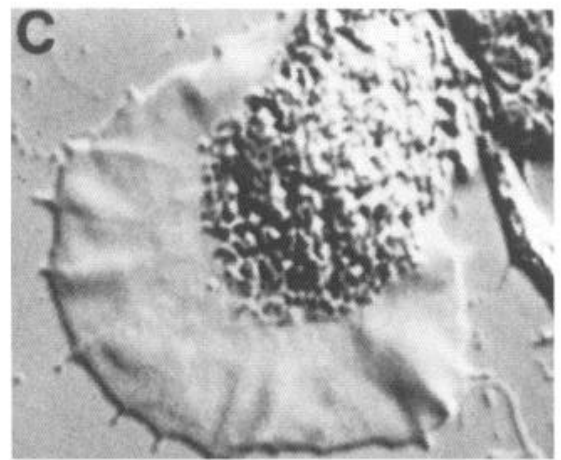

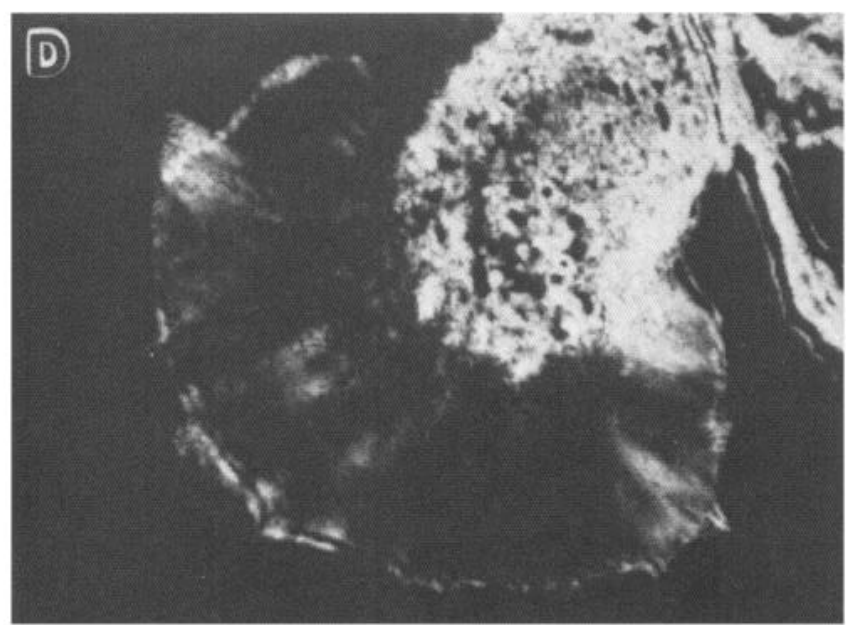

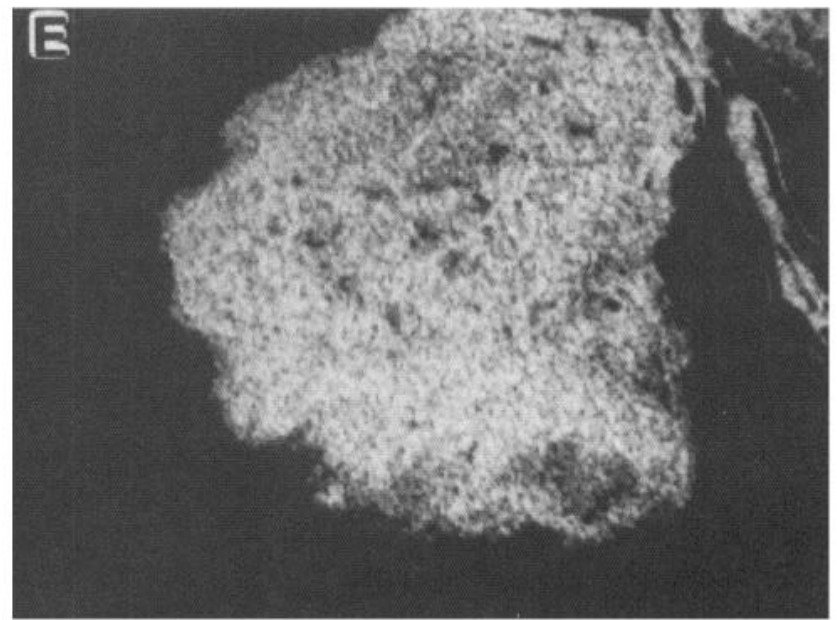

Figure 5. Forskolin treatment induces extension of the C domain. A, Video-enhanced DIC image of growth cone prior to treatment in Na-ASW control solution. Note clear demarcation between $\mathrm{P}$ and $\mathrm{C}$ domains. $B$, After $15 \mathrm{~min}$ of continuous exposure to Na-ASW containing $50 \mu \mathrm{M}$ forskolin and $2 \mathrm{~mm}$ theophylline. $C$, Recovery after Na-ASW wash. Note that the P-C domain interface returns to roughly the same position as in $A$, restoring the $\mathrm{P}-\mathrm{C}$ domain ratio observed in the pretreatment control. Scale bar, $5 \mu \mathrm{m}$. D, RMSAD analysis illustrating movement under control conditions (as in $A$ and $C$ ); 20 frames, $3.5 \mathrm{sec}$ interframe interval. $E$, RMSAD analysis in the presence of forskolin/theophylline (as in $B$ ).

that many of the individual spherical organelles that are evident in the single-frame image (Fig. $2 A$ ) are not evident in the averaged image, and the longitudinal (stable) ridges along which these organelles are transported are clearly delineated.

\section{Retrograde waves in lamellae}

Although there is little evidence of directed organelle movement in lamellae under control conditions, this region of the growth cone is not quiescent. Time-lapse recordings reveal the presence of a different type of motility in this region of the cell: lamellae undulate in retrograde waves. Prominent retrograde wave activity is observed in lamellae during periods of extension. The waves appear to originate at the distal veil margins and propagate toward the core of the growth cone.

The mottled difference patterns evident in the veil region of the growth cone in Figure 2, B, $C$, is due to changes in lamella shape that occurred during the sampling intervals. The video image sequences in Figure 4 further illustrate the dynamic nature of retrograde waves in 2 different cells. A variety of wave sizes were observed; Figure $4, A, B$ and $C, D$, illustrates examples of larger and smaller retrograde waves, respectively. An area of interest (AOI) was chosen for wave analysis in each cell (Fig. 4, $A, C$, black rectangles) and a digital movie of the AOI was recorded using $2 \mathrm{sec}$ interframe intervals. Retrograde waves appear as diagonal band patterns across the sequential video montages of the AOI movie (Fig. 4, $B, D$ ). Wave velocity can be calculated directly from the slope of the wave bands. Velocities did not appear to differ between the macro and micro wave types $(0.076$ and $0.072 \mu \mathrm{m} / \mathrm{sec}$ for Fig. $4, A, B$ and $C, D$, respectively). Although the mechanism and function of these waves is not yet known, we suspect they are closely related to the mechanism of lamellar spreading and extension. Such waves are most likely to be observed during periods of active neurite growth, and least likely to be observed on growth cones that have stopped growing. Similar retrograde lamellar ruffling has been reported in other motile cells (Alberts et al., 1983; Oster, 1984).

\section{Cyclic AMP effects on growth cone structure and organelle transport}

After equilibration in Na-ASW, growth cones were treated with forskolin plus a phosphodiesterase (PDE) inhibitor or a PDE- 
Figure 6. Effects of $50 \mu \mathrm{M}$ forskolin and $2 \mathrm{~mm}$ theophylline (FSK/TH) in the presence or absence of $10 \mathrm{~mm}$ external calcium. Color RMSAD images as in Figure 3. A, $10 \mathrm{Ca}$-ASW control. $B$, After FSK/TH treatment (as in Fig. 5). $C$, Zero Ca-ASW control. D, After treatment with FSK/TH (as in Fig. 7). Note apparent $\mathrm{Ca}$-dependent changes in relative lamella motility under control conditions.

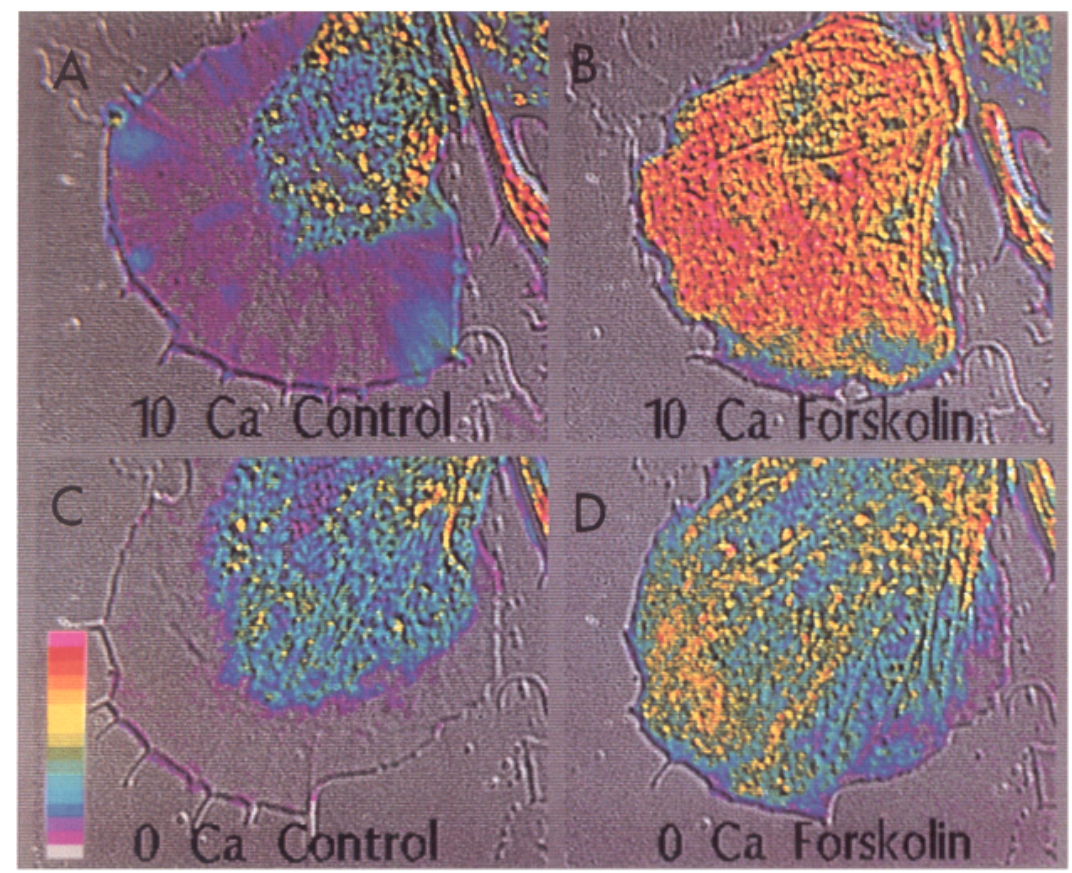

resistant cAMP analog. Typical effects of cAMP elevation on organelle distribution, observed with video-enhanced DIC, are illustrated in Figures 5, 7, and 8.

Figure $5 \mathrm{~A}$ illustrates a growth cone under control conditions (Na-ASW, Control). After $15 \mathrm{~min}$ of treatment with forskolin plus theophylline, the area of the growth cone in which organelle movement was observable expanded to occupy essentially all of what was the lamella (P domain) prior to drug treatment (Fig. $5 B, \mathrm{FSK} / \mathrm{TH}$ ). The effects are totally reversible (Fig. $5 C$, Recovery). Under these conditions, organelles begin to migrate distally within 3-4 min after forskolin application, with maximal effects obtained in 8-12 min. Phenomenologically, the effect appears to be an advance of the C-type of cytoplasmic domain: during treatment, organelles progressively migrate on linear trajectories toward the distal edge of the cell, suggesting the presence of newly formed, dense microtubule arrays in a region that had P-type cytoplasmic morphology (low microtubule density) before treatment. RMSAD motion analysis of the same growth cone under control conditions shows robust $\mathrm{C}$ domain movement and a mottled pattern of lesser average movement in the lamella due to retrograde wave actions (Fig. 5D and Fig. 6A). After treatment with forskolin and theophylline, the RMSAD image indicates movement throughout the growth cone due to the drug-induced spread of organelle transport (Fig. $5 E$ and Fig. $6 B)$. In addition to the distal spread of directed organelle transport, other effects noted after forskolin treatment included the inhibition of growth and retrograde wave activity (for up to 2 $\mathrm{hr}$ of drug exposure). It may be of interest to note here that serotonin application has been observed to reversibly suppress neurite elongation in an identified Helisoma neuron (Haydon et al., 1984).

We also tested the effects of BT-cAMP, a potent membranepermeant and phosphodiesterase-resistant cAMP analog that is effective in Aplysia neurons (Kaczmarek and Strumwasser, 1984). Changes in organelle transport and distribution effected by BTcAMP were essentially identical to those described above for forskolin and PDE inhibitor treatments (see Fig. 10).
Forskolin treatment alone, which in the absence of a PDE inhibitor produces only very small $(<40 \%)$ changes in cAMP levels in bag cell neurons (J. A. Kauer and L. K. Kaczmarek, unpublished observations), was found to have little effect on organelle distribution. Effects identical to those shown in Figure $5 E$ were; however, observed when forskolin was applied with a non-methyl xanthine PDE inhibitor (50 $\mu \mathrm{M}$ RO-20-1724). Application of either RO-20-1724 or theophylline alone caused some organelle migration into growth cone tips, as might be expected if basal cAMP levels rise after inhibition of cAMP degradation. The effects of PDE inhibitors alone were; however, much smaller than those observed in response to both forskolin and PDE inhibitor.

\section{Cyclic AMP effects do not depend on Ca influx}

Elevation of intracellular cAMP is known to modulate K currents in bag cell neurons in vitro causing increased excitability and, in some cases, eliciting spontaneous firing of action potentials that have a large calcium component (Kaczmarek and Strumwasser, 1981; Strong, 1984; Strong and Kaczmarek, 1986). Continuous firing of action potentials could result in a significant $\mathrm{Ca}$ influx. There is also evidence from other cell types that voltage-dependent $\mathrm{Ca}$ channels are present in growth cone membranes (Greenberg and Spector, 1984; Freeman et al., 1985; MacVicar and Llinas, 1985; cf. Belardetti et al., 1986). An increase in Ca concentration in growth cones might alter microtubule dynamics and/or cytoskeleton-organelle interactions by a variety of $\mathrm{Ca}$-dependent or $\mathrm{Ca}$-calmodulin-dependent mechanisms (Purich et al., 1981; Yamamoto et al., 1983; Bernstein and Bamburg, 1985; Vallano et al., 1985). We therefore carried out 2 kinds of experiments to assess whether the effects of forskolin on bag cell neuron growth cones might be secondary to changes in electrical properties leading to enhanced $\mathrm{Ca}$ entry: (1) We tested the actions of forskolin in the absence of extracellular $\mathrm{Ca}$; (2) we depolarized bag cell neurons by elevating external $\mathrm{K}$ concentrations in the presence and absence of external Ca. 
Ca-Free ASW Control

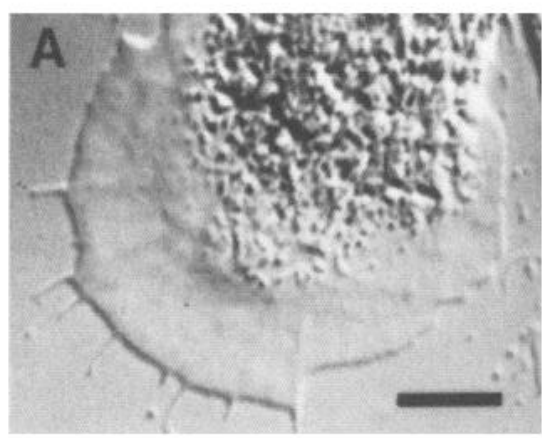

FSK / TH

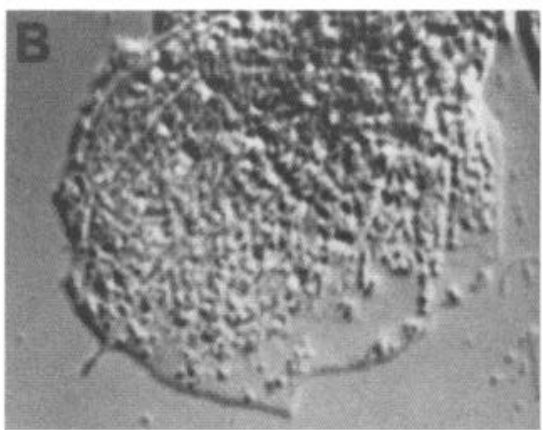

Recovery

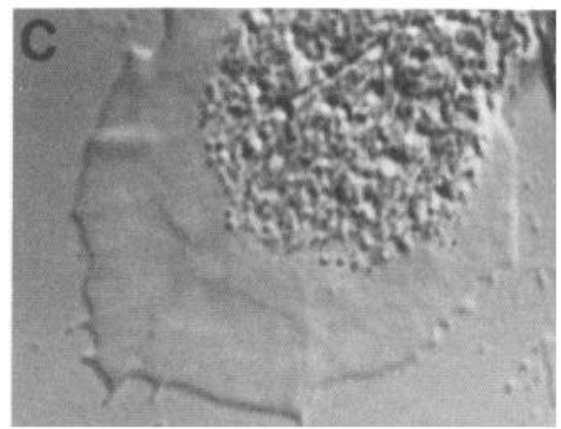

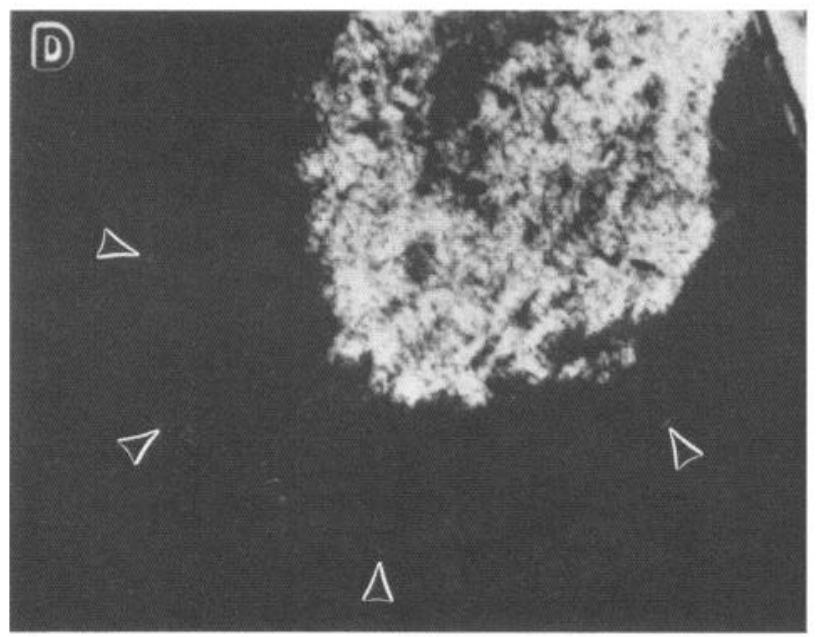

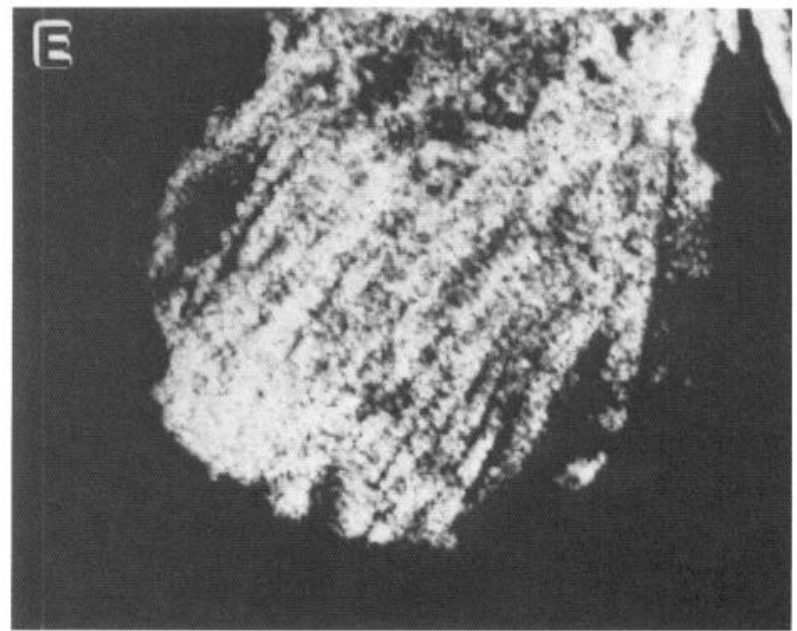

Figure 7. Cyclic AMP effects do not depend on Ca influx. A, Video-enhanced DIC image of a growth cone after equilibration in Ca-free ASW (Ca-free ASW control). B, After treatment with $50 \mu \mathrm{m}$ forskolin and $2 \mathrm{~mm}$ theophylline. Note presence of linear organelle arrays. $C$, Recovery after wash in Ca-free ASW. Scale bar, $5 \mu \mathrm{m}$. D, RMSAD of growth cone in Ca-free ASW. Arrowheads mark distal border of lamella, which is barely visible because of absence of pronounced ruffling under these conditions; 20 frames, 3.5 sec interframe interval. $E$, RMSAD in the presence of forskolin/theophylline.

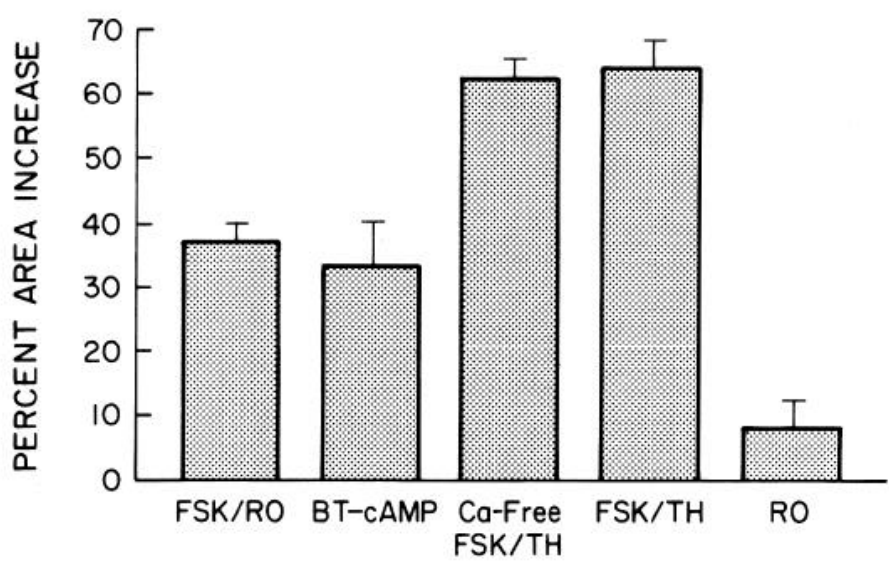

Figure 8. Summary of cAMP effects on C domain redistribution. Area increases were calculated as described in Figure 9. Test conditions: 50 $\mu \mathrm{M}$ forskolin, $50 \mu \mathrm{M}$ RO-20-1724 (FSK/RO; $n=10) ; 500 \mu \mathrm{M} 6-N$-butyl8-benzylthio-cAMP ( $B T$-cAMP; $n=2)$ ); $50 \mu \mathrm{M}$ forskolin, $2 \mathrm{mM}$ theophylline in Ca-free ASW (Ca-Free FSK/TH; $n=3$ ); $50 \mu \mathrm{M}$ forskolin, $2 \mathrm{~mm}$ theophylline in Na-ASW $(F S K / T H ; n=2) ; 50 \mu \mathrm{M} \mathrm{RO}-20-1724$ $(R O: n=2)$.
We found that omitting external Ca from the external solutions did not inhibit the effects of forskolin. A typical response to application of forskolin plus theophylline in Ca-free medium is illustrated in Figure 7. Similar results were obtained when 1 mм EGTA was added to Ca-free solutions to buffer free external $\mathrm{Ca}$ to below $10^{-8} \mathrm{M}$. These findings rule out the possibility that the observed effects on organelle distribution are due to influx of external $\mathrm{Ca}$. Changes in intracellular calcium concentration as a result of altered $\mathrm{Ca}$ buffering or release from intracellular stores are not eliminated as possible mechanisms by these experiments.

Some subtle differences were noted in the effects of forskolin treatment in the absence of external $\mathrm{Ca}$, mainly in the organization of transport within the extended $\mathrm{C}$ domain. When experiments were performed using Na-ASW containing $10 \mathrm{~mm}$ $\mathrm{Ca}$, the most obvious effect of raising cAMP levels was progressive organelle migration into the distal growth cone tip. Although migration usually proceeded along linear trajectories, there was always a population of organelles that exhibited nonlinear, apparently random, movements. When the same experiments were performed in Ca-free ASW, drug-induced organelle migration always appeared highly linear, with little evidence of 
organelle escape from linear transport restraints. These qualitative differences in organelle movement behavior are evident when comparing the RMSAD/forskolin images obtained in the presence and absence of external $\mathrm{Ca}$. The highly linear character of forskolin-induced organelle transport in Ca-free external medium results in the striped RMSAD motility patterns of Figure $7 E$. By contrast, the motility pattern of Figure $5 E$, produced by the same drug treatment in the presence of $10 \mathrm{~mm}$ external $\mathrm{Ca}$, is smeared due to averaging of many more nonlinear motile events. These Ca-dependent differences in the quality of organelle movement may reflect changes in organelle-microtubule interactions. For example, the presence of Ca may increase the probability of transient organelle associations with a linearly organized transport substrate; alternatively, transport substrates may be less linear in the presence of $\mathrm{Ca}$. These possibilities await further investigation. Figure $6, A-D$, compares forskolin effects on growth cone motility in the presence and absence of external Ca using RMSAD-DIC overlays. Note that under control conditions there appears to be less veil motility in the absence of external $\mathrm{Ca}$. Figure 8 summarizes all of the cAMPmediated effects on organelle distribution and movement described above. Bars represent average treatment-induced increases in the percentage of $\mathrm{C}$ domain within growth cones under each experimental condition. The method used to calculate the changes in $\mathrm{C}$ domains and normalize for variations in growth cone size is described in Figure 9.

A second test for $\mathrm{Ca}$ mediation of forskolin effects involved comparison of forskolin effects with those resulting from elevation of cytoplasmic $\mathrm{Ca}$. To elevate intracellular $\mathrm{Ca}$, cells were depolarized by exposure to ASW solutions containing 100-400 $\mathrm{mm} \mathrm{K}$ and $10 \mathrm{~mm} \mathrm{Ca}$. A range of effects were observed; none of these; however, mimicked the effects of forskolin. The acute effects of $100 \mathrm{~mm}$ K-ASW application in one cell are shown in the image sequence in Figure 10. Figure $10 A$ illustrates 2 growth cones in $\mathrm{Na}$-ASW just before application of the elevated $\mathrm{K}$ solution. Three seconds after $\mathrm{K} / \mathrm{Ca}$ exposure, there was a rapid disappearance of spherical organelles from the growth cone core (C domain) accompanied by the appearance of vacuole-like structures in the same region (Fig. 10, $B, C$ ). Existing filopodia extended rapidly, and in some regions filopodia sprouted de novo, extending $7-10 \mu \mathrm{m}$ in $20 \mathrm{sec}$. Continued $\mathrm{K}$ exposure resulted in further depletion of spherical organelles, retraction of filopodia, redistribution of vacuole-like structures, and the apparent complete disassembly of the $\mathrm{C}$ domain in the growth cone regions examined (Fig. 10, D, E).

Residual organelle transport in the growth cone becomes less linearly organized during $\mathrm{K}$ depolarization. After $12 \mathrm{~min}$ of $\mathrm{K}$ exposure, this cell was returned to $\mathrm{Na}$-ASW control solution (Fig. 10E), and within several minutes organelles moving on linear paths began to repopulate the growth cone (Fig. 10F). Continued perfusion with $\mathrm{Na}-\mathrm{ASW}$ usually resulted in reconstruction of the growth cone's $\mathrm{C}$ domain: in essence, reconstitution of highly organized linear organelle movements and the clear delineation between the $\mathrm{C}$ and $\mathrm{P}$ domains. These effects were not observed if $\mathrm{Ca}$ was omitted from the elevated $\mathrm{K}$ test solutions.

In some cases exposure to $100 \mathrm{~mm} \mathrm{~K}$-ASW did not cause such dramatic effects: there was no clear decrease in the number of spherical organelles; rather, organelles tended to spread into the P domain with intermittent, nonlinear movements. Disruption of linear organelle transport was evident, but incomplete and vacuole-like structures did not form. Exposure to higher $\mathrm{K}$
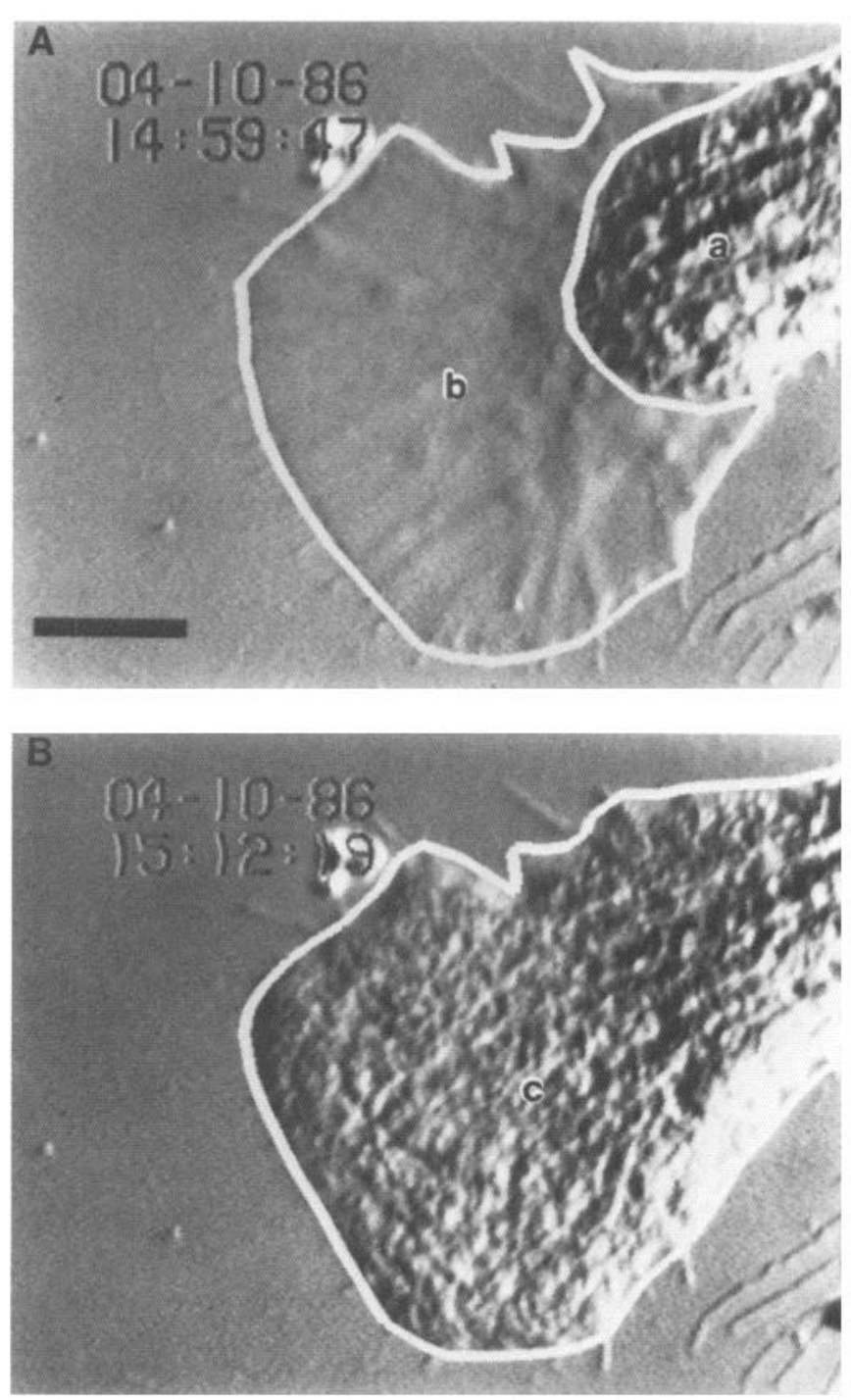

Figure 9. Calculation of cytoplasmic domain area changes. $A, B$, Video-enhanced DIC images of a growth cone in Ca-free ASW $(A)$; after treatment with $50 \mu \mathrm{M}$ forskolin and $2 \mathrm{~mm}$ theophylline $(B)$. Area calculations were made by integrating the pixels within $\mathrm{C}$ and $\mathrm{P}$ domain boundaries (outlined areas) under each condition. The proximal boundary of the growth cone was taken to be a line connecting the most proximal extensions of the lamella on either side of the cone. Area changes were normalized by the total area of the growth cone $(a+b)$ : $\% \mathrm{C}$ domain area change $=(c-a) /(a+b) \times 100$. Scale bar, $5 \mu \mathrm{m}$.

concentrations could sometimes reinstate the more dramatic effects described above. This may have reflected cell-to-cell variations in resting potentials or different densities of $\mathrm{Ca}$ channels in individual growth cones.

Two major points clearly differentiate the effects of elevated cAMP from those of K depolarization: (1) Forskolin effects are independent of external $\mathrm{Ca}$, whereas the $\mathrm{K}$ effects described above are absent when cells are depolarized with $\mathrm{Ca}$-free high-K solutions; (2) K/Ca-induced organelle spreading is characterized predominantly by intermittent, nonlinear organelle movements, whereas forskolin-induced organelle spreading is essentially a linearly organized process.

\section{Discussion}

We have found that treatments known to elevate intracellular cAMP in bag cell neurons dramatically and rapidly alter growth 

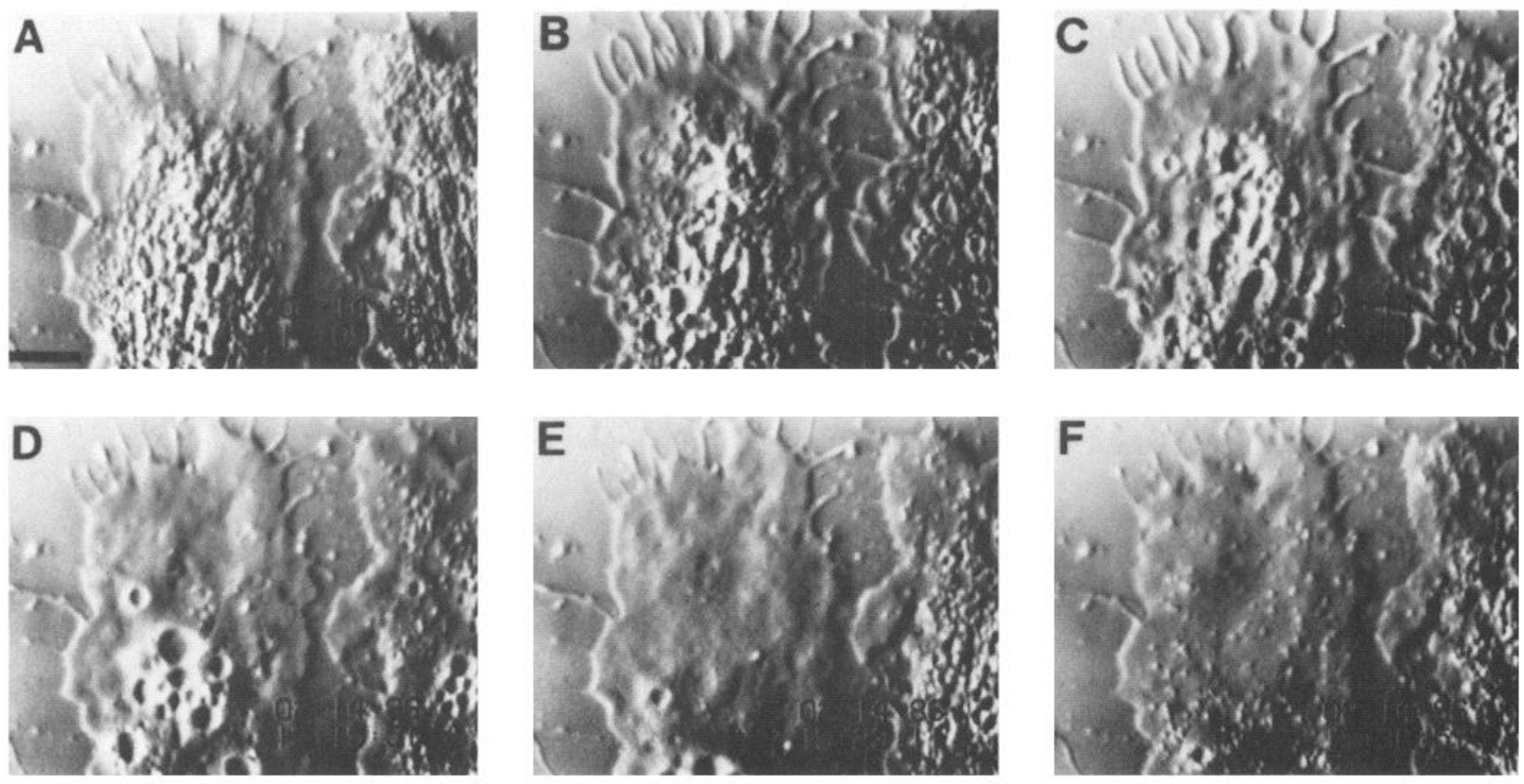

Figure 10. $\mathrm{K}^{+}$depolarization affects growth cone structure. $A-F$, Sequential video-enhanced DIC images obtained after exposing cell to 100 mM K-ASW. A, Pretreatment control in Na-ASW. B, Filopodia rapidly extend and swell immediately after $\mathrm{K}$ treatment and vacuole-like profiles appear. Continued $\mathrm{K}$ exposure results in disappearance of organelles from the $\mathrm{C}$ domain $(C, D)$. $E$, Cell is returned to Na-ASW after 12 min in elevated $\mathrm{K}$. $F$, Organelles reappear in growth cone as cell recovers. Scale bar, $5 \mu \mathrm{m}$.

cone structure and motility. Within minutes after treatment, the clear demarcation between the $\mathrm{C}$ domain of the growth cone core and the $\mathrm{P}$ domain characteristic of the lamellipodium disappears. This is due to the rapid migration of organelles into the distal margin of the lamella. Lamellae are tranformed from relatively organelle-free areas, devoid of all but intermittent transport, into club-shaped endings packed with organelles, mainly peptidergic secretory granules. These effects are not dependent on external calcium and persist when cells have been bathed in Ca-free solutions containing EGTA, conditions that would also tend to deplete intracellular $\mathrm{Ca}$. These observations strongly suggest that the major effect of elevations of cAMP that we observe - the induced spread of directed organelle transport into distal growth cone margins-does not depend on changes in intracellular $\mathrm{Ca}$. Further experiments employing techniques to directly buffer and monitor intracellular $\mathrm{Ca}$ will; however, be required to definitively test whether local changes in $\mathrm{Ca}$ ion concentration contribute to these effects.

Some comments can be made regarding how $\mathrm{Ca}$ affects the quality of observed organelle movements. In general, the presence of $\mathrm{Ca}$ in the external medium tended to increase the occurrence of nonlinear, intermittent organelle movements. This was most evident when comparing time-lapse recordings or RMSAD motion analysis of forskolin/PDE inhibitor experiments carried out in the presence and absence of external $\mathrm{Ca}$. In the absence of $\mathrm{Ca}$, the cAMP-dependent effects can be described as a simple spread of linearly directed organelle movements into distal growth cone margins. In contrast, drug exposure in the presence of $\mathrm{Ca}$ always induced a component of random organelle movement along with the spread of linear, directed transport. The fact that forskolin exposure can stimulate spontaneous firing of action potentials in bag cell neurons suggests that the randomization of organelle movements may be due to $\mathrm{Ca}$ influx through voltage-dependent channels. Some of our observations of organelle behavior after $\mathrm{K}$ depolarization in the presence of $\mathrm{Ca}$ also support this hypothesis; however, the effects observed after $\mathrm{K} / \mathrm{Ca}$ exposure are complex and need to be characterized further.

Since it is likely that microtubules provide the substrate upon which organelles move during fast transport of the type described here (Schnapp et al., 1985; Vale et al., 1985a-c; Schnapp and Reese, 1986), alteration of microtubule dynamics and microtubule-organelle interactions are 2 possible explanations for the cAMP-induced effects on directed organelle transport reported here. Although little is known regarding regulation of microtubule-organelle interactions, cAMP effects on microtubule dynamics have been described and are discussed below.

In bag cell neurons, the distal microtubule front resides, for the most part, at the C-P domain interface. In addition, it has recently been demonstrated that microtubule elongation in growing neurons is primarily the result of tubulin subunit assembly at distal (plus) microtubule ends (Bamburg et al., 1986). Thus, regulation of microtubule assembly could provide a mechanism for the cAMP-dependent effects we describe here. Phosphorylation of microtubule-associated proteins (MAPs) by cAMP-dependent protein kinase(s) is thought to be involved in the regulation of microtubule dynamics (Jameson and Caplow, 1981; Tash et al., 1981; Theurkauf and Vallee, 1982, 1983; Vallano et al., 1985), providing some precedent for such a mechanism, although a clear physiological role for MAP phosphorylation in the regulation of microtubule function has yet to be established.

Under control conditions we observe little organelle transport into lamellae, suggesting that competent microtubule transport 
substrates are not normally abundent in this domain. This suggestion is supported by the low density of microtubules observed in lamellae in thin sections of growth cones fixed under control conditions (cf. Fig. 1), and by results from studies in which microtubule distribution in growth cones has been examined with tubulin immunofluorescence ( $P$. Forscher, unpublished observations). It is not likely then, that many microtubule arrays exist in lamellae under control conditions. Our observations suggest that forskolin treatment results in a net extension of the microtubule arrays into the growth cone, promoting transport of many organelles into what was previously a P-type domain.

Alterations in cytoskeletal components that might relax transport restraints on organelles at the C-P domain interface could also contribute to the effects of cAMP elevation. For example, decreases in actin cross-linking or actin-microtubule associations resulting from phosphorylation (Selden and Pollard, 1983) might "loosen" the actin lattice present in the P domain, thus facilitating distal organelle migration by reducing friction between organelles and the surrounding cytoplasmic matrix.

We have demonstrated that cAMP treatment causes rapid changes in organelle distribution in bag cell growth cones, resulting in the accumulation of neurosecretory granules in distal neurite endings. It is tempting to speculate that during development, the elevation of cAMP signals target recognition and triggers the transformation of growth cones into mature neurosecretory terminals. In the adult animal, cAMP regulates neuropeptide synthesis and prohormone processing, and also modulates bag cell electrical activity during periods of prolonged secretion. Perhaps the induced changes in peptide granule transport we have described here are yet another aspect of cAMP's role in coordinating the secretory response in bag cell neurons in vivo.

\section{References}

Alberts, B., D. Bray, J. Lewis, M. Raff, K. Roberts, and J. D. Watson (1983) Molecular Biology of the Cell, pp. 589-605, Garland, New York.

Allen, R. D., N. S. Allen, and J. L. Travis (1981) Video-enhanced contrast, differential interference contrast (AVEC-DIC) microscopy: A new method capable of analyzing microtubule-related motility in the reticulopodial network of Allogromia laticollaris. Cell Motil. 1 . 291-302.

Allen, R. D., D. G. Weiss, J. H. Hayden, D. T. Brown, H. Fujiwake, and M. Simpson (1985) Gliding movement of and bidirectional organelle transport along single native microtubules from squid axoplasm: Evidence for an active role of microtubules in cytoplasmic transport. J. Cell Biol. 100: 1736-1752.

Azhderian, E., and L. K. Kaczmarek (1986) Onset of discharge and elevations of cyclic AMP stimulate prohormone processing in bag cell neurons. J. Cell Biol.

Bamberg, J. R., D. Bray, and K. Chapman (1986) Assembly of microtubules at the tip of growing axons. Nature 321: 788-790.

Belardetti, F., S. Schacher, and S. Siegelbaum (1986) Action potentials and single channel currents recorded from growth cones of Aplysia neurones in culture. J. Physiol. (Lond.) 374: 289-313.

Bernstein, B. W., and J. R. Bamburg (1985) Reorganization of actin in depolarized synaptosomes. J. Neurosci. 5: 2565-2569.

Bridgman, P. C., B. Kachar, and T. S. Reese (1986) The structure of cytoplasm in directly frozen cultured cells. II. Cytoplasmic domains associated with organelle movements. J. Cell Biol. 102: 1510-1512.

Bruehl, C. L., and R. W. Berry (1985) Regulation of synthesis of the neurosecretory egg-laying hormone of Aplysia: Antagonistic roles of calcium and cyclic adenosine $3^{\prime}: 5^{\prime}$-monophosphate. J. Neurosci. 5: $1233-1238$.

Cohan, C., and S. B. Kater (1986) Suppression of neurite elongation and growth cone motility by electrical activity. Science $232: 1638-$ 1640 .
Frazier, W. T., E. R. Kandel, I. Kupferman, R. Waziri, and R. E. Coggeshall (1967) Morphological and functional properties of identified neurons in the abdominal ganglion of Aplysia californica. J. Neurophysiol. 30: 1288-1351.

Freeman, J. A., P. B. Manis, G. J. Snipes, B. N. Mayes, P. C. Samson, J. P. Wikswo, Jr., and D. B. Freeman (1985) Steady growth cone currents revealed by a novel circularly vibrating probe: A possible mechanism underlying neurite growth. J. Neurosci. Res. 13: 257284.

Greenberg, A., and I. Spector (1984) Voltage-gated ion channels in neuronal growth cones. Soc. Neurosci. Abstr. 10:938.

Haydon, P. G., D. P. McCobb, and S. B. Kater (1984) Serotonin selectively inhibits growth cone motility and synaptogenesis of specific identified neurons. Science 226: 561-564.

Inoue, S. (1981) Video image processing greatly enhances contrast, quality and speed in polarization-based microscopy. J. Cell Biol. 89: 346-356.

Jameson, L., and M. Caplow (1981) Modification of microtubule steadystate dynamics by phosphorylation of the microtubule-associated proteins. Proc. Natl. Acad. Sci. USA 78: 3413-3417.

Jones, P. G., S. J. Rosser, and A. G. M. Bulloch (1986) Glutamate enhancement of neurite outgrowth in Helisoma neurons. Soc. Neurosci. Abstr. 12: 509.

Kaczmarek, L. K., and F. Strumwasser (1981) The expression of longlasting afterdischarge by isolated Aplysia bag cell neurons. J. Neurosci. 1: $626-634$.

Kaczmarek, L. K., and F. Strumwasser (1984) A voltage clamp analysis of currents underlying cAMP-induced membrane modulation in isolated peptidergic neurons of Aplysia. J. Neurophysiol. 52: 340349.

Kaczmarek, L. K., K. Jennings, and F. Strumwasser (1978) Neurotransmitter modulation, phosphodiesterase inhibitor effects, and cyclic AMP correlates of afterdischarge in peptidergic neurites. Proc. Natl. Acad. Sci. USA 75: 5200-5204.

Kaczmarek, L. K., M. Finbow, J. P. Revel, and F. Strumwasser (1979) The morphology and coupling of Aplysia bag cells within the abdominal ganglion and in cell culture. J. Neurobiol. 10: 535-550.

Kaczmarek, L. K., K. R. Jennings, F. Strumwasser, A. C. Nairn, U. Walter, F. D. Wilson, and P. Greengard (1980) Microinjection of catalytic subunit of cyclic AMP-dependent protein kinase enhances calcium action potentials of bag cell neurons in cell culture. Proc. Natl. Acad. Sci. USA 77: 7487-7491.

Koonce, M., and M. Schliwa (1985) Bidirectional organelle transport can occur in cell processes that contain single microtubules. J. Cell Biol. 100: 322-326.

Kreiner, T., W. Sossin, and R. Scheller (1986) Localization of Aplysia neurosecretory peptides to multiple populations of dense core vesicles. J. Cell Biol. 102: 769-782.

Kupferman, I., and E. R. Kandel (1970) Electrophysiological properties and functional interconnections of two symmetrical neurosecretory clusters (bag cells) in abdominal ganglion of Aplysia. J. Neurophysiol. 33: 865-876.

Letourneau, P. C. (1982) Nerve fiber growth and its regulation by extrinsic factors. In Neuronal Development, N. Spitzer, ed., pp. 213254, Plenum, New York.

Letourneau, P. C. (assisted by A. H. Ressler) (1983) Differences in the organization of actin in the growth cones compared with the neurites of cultured ncurons from chick cmbryos. J. Ccll Biol. 97: 963-973.

Letourneau, P. C. (1985) Axonal growth and guidance. In Molecular Bases of Neural Development, G. M. Edelman, W. E. Gall, and W. M. Cowan, eds., pp. 269-293, John Wiley \& Sons, New York.

Luftig, R. B., P. N. McMillan, J. A. Wetherbee, and R. R. Weihing (1977) Increased visualization of microtubules by an improved fixation procedure. J. Histochem. Cytochem. 25: 175-187.

MacVicar, B. A., and R. R. Llinas (1985) Barium action potentials in regenerating axons of the Lamprey spinal cord. J. Neurosci. Res. 113: 323-336.

McDonald, K. (1984) Osmium ferricyanide fixation improves microfilament preservation and membrane visualization in a variety of animal cell types. J. Ultrastruct. Res. 86: 107-118.

Moore, M. J. (1975) Removal of glass coverslips from cultures flat embedded in epoxy resins using hydrofluoric acid. J. Microsc. 104: 205-207.

Oster, G. F. (1984) On the crawling of cells. J. Embryol. Exp. Morphol. 83: $329-364$. 
Purich, D. L., B. J. Terry, H. D. White, B. A. Coughlin, T. L. Karr, and D. Kristofferson (1981) Microtubule associated protein phosphorylation and calcium-ion regulation of bovine brain microtubule selfassembly. In Cold Spring Harbor Conference on Cell Proliferation, No. 8, Cold Spring Harbor Lab, Cold Spring Harbor, NY, pp. 11431155.

Schnapp, B. J., and T. S. Reese (1986) New developments in understanding rapid axonal transport. Trends Neurosci. 9: 155-162.

Schnapp, B. J., R. D. Vale, M. P. Sheetz, and T. S. Reese (1985) Single microtubules from squid axoplasm support bidirectional movement of organelles. Cell 40: 455-462.

Selden, C. S., and T. D. Pollard (1983) Phosphorylation of microtubule-associated proteins regulates their interaction with actin filaments. J. Biol. Chem. 258: 7064-7071.

Strong, J. A. (1984) Modulation of potassium current kinetics in bag cell neurons of Aplysia by an activator of adenylate cyclase. J. Neurosci. 4: $2772-2783$.

Strong, J. A., and L. K. Kaczmarek (1986) Multiple components of delayed potassium current in peptidergic neurons of Aplysia: Modulation by an activator of adenylate cyclase. J. Neurosci. 6: 814-822.

Stuart, D. K., A. Y. Chiu, and F. Streumwasser (1980) Neurosecretion of egg-laying hormone and other peptides from electrically active bag cell neurons of Aplysia. J. Neurophysiol. 43: 488-498.

Tash, J. S., L. Lagace, D. R. Lynch, S. M. Cox, B. R. Brinkley, and A. R. Means (1981) Role of cAMP-dependent protein phosphorylation in microtubule assembly and function. In Cold Spring Harbor Conference on Cell Proliferation, No. 8, Cold Spring Harbor Lab, Cold Spring Harbor, NY, pp. 1171-1184.

Theurkauf, W. E., and R. B. Vallee (1982) Molecular characterization of the CAMP-dependent protein kinase bound to microtubule-associated protein 2. J. Biol. Chem. 257: 3284-3290.

Theurkauf, W. E., and R. B. Vallee (1983) Extensive cAMP-dependent and cAMP-independent phosphorylation of microtubule-associated protein 2. J. Biol. Chem. 258: 7883-7886.

Tosney, K. W., and N. K. Wessells (1983) Neuronal motility: The ultrastructure of veils and microspikes correlates with their motile activities. J. Cell Sci. 61: 389-411.

Vale, R. D., T. S. Reese, and M. P. Sheetz (1985a) Identification of a novel force-generating protein, kinesin, involved in microtubule-based motility. Cell 42: 39-50.

Vale, R. D., B. J. Schnapp, T. S. Reese, and M. P. Sheetz (1985b) Movement of organelles along filaments dissociated from the axoplasm of the squid giant axon. Cell 40: 449-454.

Vale, R. D., B. J. Schnapp, T. S. Reese, and M. P. Sheetz (1985c) Organelle, bead, and microtubule translocations promoted by soluble factors from the squid giant axon. Cell 40:559-569.

Vallano, M. L., J. R. Goldenring, T. M. Buckholz, R. E. Larson, and R. DeLorenzo (1985) Scparation of endogenous calmodulin- and cAMP-dependent kinases from microtubule preparations. Proc. Natl. Acad. Sci. USA 82: 3203-3206.

Yamada, K. M., B. S. Spooner, and N. K. Wessells (1971) Ultrastructure and function of growth cones and axons of cultured nerve cells. J. Cell Biol. 49: 614-635.

Yamamoto, H., K. Fukunaga, E. Tanaka, and E. Miyamoto (1983) $\mathrm{Ca}^{2+}$ - and calmodulin-dependent phosphorylation of microtubuleassociated protein 2 and tau factor, and inhibition of microtubule assembly. J. Neurochem. 41: 1119-1125. 